Article

\title{
Retrieval of Aerosol Components Using Multi-Wavelength Mie-Raman Lidar and Comparison with Ground Aerosol Sampling
}

\author{
Yukari Hara ${ }^{1}$, Tomoaki Nishizawa ${ }^{2, *}$, Nobuo Sugimoto ${ }^{2}$ (), Kazuo Osada ${ }^{3}$, Keiya Yumimoto ${ }^{1}$, \\ Itsushi Uno ${ }^{1}$, Rei Kudo ${ }^{4}$ and Hiroshi Ishimoto ${ }^{4}$ \\ 1 Research Institute for Applied Mechanics, Kyushu University, 6-1 Kasuga Park, Fukuoka 816-8580, Japan; \\ yhara@riam.kyushu-u.ac.jp (Y.H.); yumimoto@riam.kyushu-u.ac.jp (K.Y.); uno@riam.kyushu-u.ac.jp (I.U.) \\ 2 Center for Environmental Measurement and Analysis, National Institute for Environmental Studies, \\ 16-2 Onogawa, Tsukuba 305-8506, Japan; nsugimot@nies.go.jp \\ 3 Graduate School of Environmental Studies, Nagoya University, Furo-cho Chikusa-ku, Nagoya 464-8601, Japan; \\ kosada@nagoya-u.jp \\ 4 Meteorological Research Institute, Japan Meteorological Agency, 1-1 Nagamine, Tsukuba 305-0052, Japan; \\ reikudo@mri-jma.go.jp (R.K.); hiroishi@mri-jma.go.jp (H.I.) \\ * Correspondence: nisizawa@nies.go.jp; Tel.: +81-29-850-2799
}

Received: 27 April 2018; Accepted: 11 June 2018; Published: 13 June 2018

check for updates

\begin{abstract}
We verified an algorithm using multi-wavelength Mie-Raman lidar (MMRL) observations to retrieve four aerosol components (black carbon (BC), sea salt (SS), air pollution (AP), and mineral dust (DS)) with in-situ aerosol measurements, and determined the seasonal variation of aerosol components in Fukuoka, in the western region of Japan. $\mathrm{PM}_{2.5}, \mathrm{PM}_{10}$, and mass concentrations of $\mathrm{BC}$ and SS components are derived from in-situ measurements. MMRL provides the aerosol extinction coefficient $(\alpha)$, particle linear depolarization ratio $(\delta)$, backscatter coefficient $(\beta)$, and lidar ratio $(S)$ at 355 and $532 \mathrm{~nm}$, and the attenuated backscatter coefficient $\left(\beta_{\text {att }}\right)$ at $1064 \mathrm{~nm}$. We retrieved vertical distributions of extinction coefficients at $532 \mathrm{~nm}$ for four aerosol components (BC, SS, AP, and DS) using $1 \alpha_{532}+1 \beta_{532}+1 \beta_{\text {att, } 1064}+1 \delta_{532}$ data of MMRL. The retrieved extinction coefficients of the four aerosol components at $532 \mathrm{~nm}$ were converted to mass concentrations using the theoretical computed conversion factor assuming the prescribed size distribution, particle shape, and refractive index for each aerosol component. MMRL and in-situ measurements confirmed that seasonal variation of aerosol optical properties was affected by internal/external mixing of various aerosol components, in addition to hygroscopic growth of water-soluble aerosols. MMRL overestimates BC mass concentration compared to in-situ observation using the pure $\mathrm{BC}$ model. This overestimation was reduced drastically by introducing the internal mixture model of $B C$ and water-soluble substances (Core-Gray Shell (CGS) model). This result suggests that considering the internal mixture of $\mathrm{BC}$ and water-soluble substances is essential for evaluating BC mass concentration in this area. Systematic overestimation of BC mass concentration was found during summer, even when we applied the CGS model. The observational facts based on in-situ and MMRL measurements suggested that misclassification of AP as CGS particles was due to underestimation of relative humidity (RH) by the numerical model in lidar analysis, as well as mismatching of the optical models of AP and CGS assumed in the retrieval with aerosol properties in the actual atmosphere. The time variation of lidar-derived SS was generally consistent with in-situ measurement; however, we found some overestimation of SS during dust events. The cause of this SS overestimation is mainly due to misclassifying internally mixing DS as SS, implying that to consider internal mixing between DS and water-soluble substances leads to better estimation. The time-variations of $\mathrm{PM}_{2.5}$ and $\mathrm{PM}_{10}$ generally showed good agreement with in-situ measurement although lidar-derived $\mathrm{PM}_{2.5}$ and $\mathrm{PM}_{10}$ overestimated in dust events.
\end{abstract}


Keywords: Raman lidar; mixing state of aerosols; aerosols; air pollution aerosols; mineral dust; black carbon; marine aerosols

\section{Introduction}

The aerosol burden in eastern Asia is excessive compared to that of the U.S. or Europe, due to the existence of vast natural and anthropogenic sources. Therefore, different components of aerosols (e.g., dust, sulfate, nitrate, organic carbon, black carbon (BC), and marine aerosol) complexly co-exist in East Asia [1,2]. Aerosol acts as cloud condensation nuclei or ice-nucleating particles, modifying regional meteorology and climate through precipitation. Recent studies clarified that aerosol-cloud interactions (i.e., indirect effect of aerosols) play a more important role than the aerosol direct effect [3], and the uncertainty in radiative forcing on the aerosol indirect effect is still large in evaluating climate change [4]. It is essential to obtain more accurate spatial and temporal information on the chemical composition of aerosols (e.g., type and components), as well as their microphysical properties (e.g., size distribution), in order to quantitatively clarify both the direct and indirect effects, and to reduce their uncertainties in radiative forcing.

Several lidar studies have attempted to classify vertical aerosol types. For example, space-borne lidar CALIOP/CALIPSO, which is a two wavelength (532 and $1064 \mathrm{~nm}$ ) Mie-scattering lidar with depolarization measurement at $532 \mathrm{~nm}$, has provided novel aerosol type classification products including six aerosols (clean continental, clean marine, dust, polluted continental, polluted dust, and smoke) for the assumed lidar ratios [5]. These global 3D products of aerosol type classification are valuable for various environmental studies based on the chemical transport model and aerosol measurements. However, Burton et al. [6] reported that aerosol types identified by CALIPSO did not match those derived from air-borne high spectral resolution lidar (HSRL) measurements in some cases (e.g., smoke and polluted dust). Unlike Mie lidar systems, Raman lidar or HSRL can provide the lidar ratio (extinction-to-backscatter ratio (S)) because they can directly measure the extinction coefficient $(\alpha)$ and backscatter coefficient $(\beta)$. The lidar ratio is a key parameter in aerosol type classification because it is indicative of aerosol type (e.g., [7-9]). For example, the lidar ratios of urban and smoke types exceed those of marine and dust types; this difference is closely related to their distinctive optical and microphysical properties. Combining the information of lidar ratio, particle depolarization ratio $(\delta)$, and color ratio of backscatter coefficients (CR) enables better subdivided classification of aerosols. CRs are defined as $\beta_{355} / \beta_{532}$ and $\beta_{532} / \beta_{1064}$ in this paper. Burton et al. [9] developed a method to identify eight aerosol types (smoke, fresh smoke, urban, polluted maritime, maritime, dusty mix, and pure dust) using five channel data $\left(1 \alpha_{532}+2 \beta_{532,1064}+2 \delta_{532,1064}\right)$ of HSRL and verified the results of the aerosol type classification from the HSRL measurements using coincident in-situ measurements during the NASA ARCTAC field experiment.

Retrieval of aerosol components (e.g., sea salt (SS), mineral dust (DS), and BC) has been also attempted from lidar measurements. The Asian dust and aerosol lidar observation network (AD-Net) has operated two-wavelength (532 and $1064 \mathrm{~nm}$ ) Mie-scattering lidar with depolarization measurement at $532 \mathrm{~nm}$ since 2001. The AD-Net has provided extinction coefficients at $532 \mathrm{~nm}$ for spherical aerosol and DS assuming a lidar ratio using the attenuated backscatter coefficient $\left(\beta_{\text {att }}\right)$ and particle linear depolarization ratio at $532 \mathrm{~nm}$ of the Mie scattering lidar data [10]. These outputs have been widely used for epidemiological and environmental assessment in East Asia [11-14]. References [15,16] also classified DS and non DS components using backscatter coefficient and particle linear depolarization ratio at $532 \mathrm{~nm}$ in a manner analogous to Sugimoto et al. [10], however, they evaluated more detailed optical and microphysical properties (e.g., lidar ratio and effective radius) of the non DS component using a multi-wavelength Raman lidar data by improving the method described in Sugimoto et al. [10]; they characterized the non DS component as biomass burning smoke. 
More advanced aerosol component retrieval algorithms that use more parameters measured by lidar have been developed. For example, Nishizawa et al. [17] developed an algorithm to retrieve extinction coefficients at $532 \mathrm{~nm}$ for three aerosol components (DS, BC, and air pollution particles (AP)) using $\alpha$ and $\beta$ at $532 \mathrm{~nm}$ and $\beta_{\text {att }}$ at $1064 \mathrm{~nm}$ (i.e., $1 \alpha_{532}+1 \beta_{532}+1 \beta_{\text {att,1064 }}$ data) derived from HSRL measurements. AP is defined as small particles with weak light absorption, consisting of sulfates, nitrates, and organic substances without a BC component. Performance of the developed algorithms has been evaluated using theoretical error analysis and comparison with sun-photometry measurements. However, few direct comparisons have been performed with chemical measurements such as in-situ sampling measurements.

Multi-wavelength Mie-Raman lidar (MMRL) was installed to study the vertical distribution and time variation for major aerosol components in the suburbs of Fukuoka City $\left(33.52^{\circ} \mathrm{N}, 130.48^{\circ} \mathrm{E}\right)$ in western Japan, and continuous measurements by MMRL have been conducted since September 2014 [18,19]. An aerosol component retrieval algorithm was developed to retrieve the four major aerosol components (DS, BC, AP, and SS) using $1 \alpha_{532}+1 \beta_{532}+1 \beta_{\text {att,1064 }}+1 \delta_{532}$ data [18]. Long-term simultaneous in-situ aerosol chemical measurements also have been conducted continuously with high time resolution [20-25]. In this study, we first clarify the seasonal variation of derived optical properties and aerosol components in this region, and then compare aerosol component products retrieved by the algorithm using MMRL data with the in-situ aerosol chemical measurements directly to quantitatively evaluate algorithm performance.

\section{Observation and Method}

\subsection{Lidar Measurement}

Analysis flow and main parameters evaluated in this study are depicted in Figure 1. The system, calibration, and performance of MMRL and associated data analysis have been provided in Nishizawa et al. [18]. Here, we briefly describe them. MMRL was built in a room with a transparent glass roof. This system employs a commercial compact Nd:YAG laser with second-harmonic and third-harmonic generators and a rigid biaxial configuration. Backscattered light is collected using a vertically mounted telescope. The collected light is split among the receivers at 355, 387, 532, 607, and $1064 \mathrm{~nm}$ using dichroic beam splitters. At 532 and $355 \mathrm{~nm}$, the co-polarized and cross-polarized components of the total backscatter light split using a cube polarizer are detected using photomultiplier tubes (PMTs). Nitrogen Raman backscatter signals are detected at 607 and $387 \mathrm{~nm}$ using PMTs. At $1064 \mathrm{~nm}$, the total backscatter light is detected using an avalanche photodiode (APD). Band-pass filters with a bandwidth of $1 \mathrm{~nm}$ (FWHM) are in the optical path of each detection unit to reduce contamination by the background light.

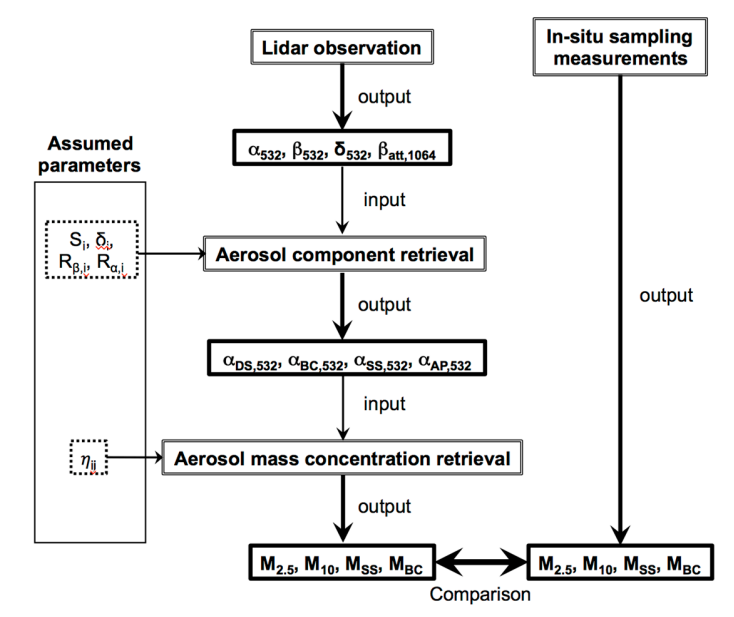

Figure 1. Analysis flow and main parameters evaluated in this study. 
Measured raw signals are averaged every $30 \mathrm{~m}$ vertically and $15 \mathrm{~min}$ temporally. The averaged signals are smoothed to improve the signal-to-noise ratio, incomplete overlap between the laser beam and the receiver field of view is corrected (overlap correction), and the averaged signals are calibrated. The extinction coefficient $\alpha$, backscatter coefficient $\beta$, lidar ratio $S$, and particle linear depolarization ratio $\delta$ are then derived from the calibrated signals. Retrieval of aerosol optical properties $(\alpha, \beta, S$, and $\delta)$ is restricted to the layer above $350 \mathrm{~m}$, due to insufficient overlap correction. We conduct photon-counting measurements for nitrogen Raman backscatter (387 and $607 \mathrm{~nm}$ ) and analog measurements for elastic backscatter $(355,532$, and $1064 \mathrm{~nm})$. No Raman channel data are available in the daytime due to strong background light. Uncertainties of the derived $\alpha, \beta, S$, and $\delta$ at 355 and $532 \mathrm{~nm}$ due to signal random noises and calibration uncertainty are less than $5 \%$, corresponding to absolute uncertainties less than $0.007 \mathrm{~km}^{-1}$ in $\alpha_{\mathrm{a}}, 0.0001 \mathrm{sr}^{-1} \mathrm{~km}^{-1}$ in $\beta_{\mathrm{a}}, 0.1 \%$ in $\delta_{\mathrm{a}}$, and $2 \mathrm{sr}$ in $\mathrm{S}_{\mathrm{a}}$.

\subsection{Aerosol Component Retrieval from Lidar Measurements}

The algorithm to retrieve extinction coefficients at $532 \mathrm{~nm}$ for DS, SS, BC, and AP at each slab layer using the $\alpha, \beta$, and $\delta$ at $532 \mathrm{~nm}$ and $\beta_{\text {att }}$ at $1064 \mathrm{~nm}$ derived from the MMRL measurements has been provided in Nishizawa et al. [18]. Here, we briefly describe them and provide improvement to the algorithm. The relationship between the MMRL-derived $\alpha_{532} \beta_{532} \delta_{532}$ and $\beta_{\text {att,1064 }}$ and the estimated parameter $\alpha_{i, 532}$ at each slab layer are given by the following equations.

$$
\begin{gathered}
\alpha_{532}=\sum_{i=1}^{4} \alpha_{i, 532}, \\
\beta_{532}=\sum_{i=1}^{4} \frac{\alpha_{i, 532}}{S_{i, 532}}, \\
\delta_{532}=\sum_{i=1}^{4} \frac{\alpha_{i, 532}}{S_{i, 532}} \frac{\delta_{i, 532}}{1+\delta_{i, 532}} / \sum_{i=1}^{4} \frac{\alpha_{i, 532}}{S_{i, 532}} \frac{1}{1+\delta_{i, 532}}, \\
\beta_{\mathrm{att}, 1064}=\left(\sum_{i=1}^{4} \frac{\alpha_{i, 532}}{S_{i, 532}} \mathrm{R}_{\beta, i}+\beta_{m, 1064}\right) \exp \left\{-2 \int_{0}^{z}\left(\sum_{i=1}^{4} \frac{\alpha_{i, 532}}{S_{i, 532}} \mathrm{R}_{\alpha, i}+\alpha_{m, 1064}\right) d z\right\} .
\end{gathered}
$$

Subscript $i$ denotes aerosol components; $\mathrm{R}_{\beta, i}$ is the spectral ratio of the backscatter coefficient at $1064 \mathrm{~nm}$ to that at $532 \mathrm{~nm}$ for each aerosol component $\left(\mathrm{R}_{\beta, i}=\beta_{i, 1064} / \beta_{i, 532}\right) ; \mathrm{R}_{\alpha, i}$ is the spectral ratio of the extinction coefficient at $1064 \mathrm{~nm}$ to that at $532 \mathrm{~nm}$ for each aerosol component $\left(\mathrm{R}_{\alpha, i}=\alpha_{i, 1064} / \alpha_{i, 532}\right)$; $\beta_{m, 1064}$ and $\alpha_{m, 1064}$ are molecular backscatter and extinction coefficients at $1064 \mathrm{~nm}$, respectively, which are computed theoretically. Thus, $\alpha_{i, 532}$ can be estimated by solving the nonlinear simultaneous equation (Equation (1)), however, $S_{i}, \delta_{i}, \mathrm{R}_{\beta, i}$, and $\mathrm{R}_{\alpha, i}$ must be assumed. For this purpose, this method specifies and models the optical and microphysical properties of each aerosol component including $S_{i}$, $\delta_{i}, \mathbf{R}_{\beta, i}$, and $\mathbf{R}_{\alpha, i}$ (Table 1). Volume lognormal size distribution for each aerosol component is assumed; the mode radius and standard deviation of the size distribution and the refractive index of each aerosol component are specified. The optical properties of AP, SS, and BC are computed from the prescribed size distribution and refractive index using Mie theory. Here, $\delta_{532}$ for AP, SS, and BC is empirically assigned the value of $2 \%$. The optical properties for DS are computed using software developed by Dubovik et al. [26], assuming that the particles are spheroidal.

We improved the microphysical and optical models for AP, SS, and BC. Firstly, we considered hygroscopic growth for AP and SS based on the aerosol climatology of d'Almeida et al. [27], by which the mode radii and complex refractive indices depend on relative humidity $(\mathrm{RH})$. Thus, the models of $\mathrm{AP}$ and SS used in the retrieval change vertically depending on RH. In the actual retrieval, we used vertical distributions of RH output by the 3-D Goddard Earth-Observing System chemical transport model (GEOS-Chem) because there were no appropriate observed RH data. Secondly, we introduced an internal mixture model of BC and water-soluble substances (e.g., sulfate and nitrate), which is the core-gray shell (CGS) model proposed by Kahnert et al. [28]. Note that the conventional BC model (pure BC model) is used in the algorithm [18]. The CGS model has a structure similar to that of the 
core-shell model but with weaker light absorption. This model more accurately reproduces the optical properties (e.g., absorption coefficient) of the realistic BC aggregates encapsulated in the non-absorbing shell than other commonly used models (e.g., core-shell [29] and homogenous mixture model [30]). The volume ratio of the core (BC) to the total particle volume at the dry state was fixed at 30\%, based on aircraft measurements over the Yellow Sea and East China Sea [31]. Hygroscopic growth was considered for only the shell part of the CGS model, and the growth factor was given from the database of Hess et al. [32]. In this study, we also investigate sensitivities of the optical and microphysical models for each aerosol component assumed in the algorithm to the estimates by changing the BC model (i.e., pure BC model and CGS model), as well as the value of the parameters (e.g., mode radius) to evaluate the performance of the algorithm (see Section 3).

Table 1. Example of optical and microphysical properties of aerosol components used in the algorithm ${ }^{1}$.

\begin{tabular}{cccccc}
\hline & AP & SS & DS & Pure BC & CGS \\
\hline Mode radius $[\mu \mathrm{m}]$ & 0.10 & 1.67 & 2.00 & 0.05 & 0.11 \\
Standard deviation & 1.6 & 2.2 & 2.0 & 2.1 & 1.6 \\
$\mathrm{~S}_{532}[\mathrm{sr}]$ & 53 & 19 & 47 & 98 & 101 \\
$\mathrm{CR}_{532 / 1064}$ & 2.9 & 1.5 & 1.0 & 4.2 & 1.8 \\
$\delta_{532}[\%]$ & 2 & 2 & 30 & 2 & 2 \\
$\alpha_{532} / \mathrm{PM}_{2.5}\left[\mathrm{~m}^{2} / \mathrm{g}\right]$ & 4.3 & 0.6 & 0.2 & 9.8 & 2.7 \\
$\alpha_{532} / \mathrm{PM}_{10}\left[\mathrm{~m}^{2} / \mathrm{g}\right]$ & 0 & 1.7 & 0.5 & 0 & 0 \\
\hline
\end{tabular}

${ }^{1}$ Mode radius and standard deviation are parameters for volume lognormal size distribution. The values of the mode radius and standard deviation are in dry state $(\mathrm{RH}=0 \%)$. The values of $\mathrm{S}_{532}, \mathrm{CR}_{532 / 1064}, \delta_{532}$, and the extinction to mass conversion factors $\left(\alpha_{532} / \mathrm{PM}_{2.5}\right.$ and $\left.\alpha_{532} / \mathrm{PM}_{10}\right)$ are for $\mathrm{RH}=60 \%$; however, $\mathrm{PM}_{2.5}$ and $\mathrm{PM}_{10}$ are the mass concentrations for dry particles.

\subsection{Mass Concentration Retrieval from Lidar Measurements}

We compare aerosol mass concentration in the dry state evaluated from MMRL measurements with those derived from in-situ sampling measurements (Figure 1). Mass concentrations for particle matters $\mathrm{PM}_{2.5}\left(M_{2.5}\right)$ and $\mathrm{PM}_{10}\left(M_{10}\right)$ and sea-salt $\left(M_{S S}\right)$ and black carbon $\left(M_{B C}\right)$ are used in the comparison. Thus, we specify the ratio of mass concentration in the dry state $\left(M_{j}\right)$ to the extinction coefficient at $532 \mathrm{~nm}$ for each aerosol component $\left(\alpha_{i, 532}\right)$ (extinction to mass conversion factor: $\left.\eta_{i, j}=\alpha_{i, 532} / M_{j}\right)$ and evaluated the lidar-derived aerosol mass concentration by the following equations.

$$
\begin{gathered}
M_{2.5}=\sum_{i=1}^{4} \eta_{i, 2.5} \alpha_{i, 532} \\
M_{10}=\sum_{i=1}^{4} \eta_{i, 10} \alpha_{i, 532} \\
M_{S S}=\eta_{S S, S S} \alpha_{S S, 532} \\
M_{B C}=\eta_{B C, B C} \alpha_{B C, 532} .
\end{gathered}
$$

Subscript $j$ denotes $\mathrm{PM}_{2.5}, \mathrm{PM}_{10}$, SS and BC. The $\eta_{i, j}$ was computed using the optical and microphysical model for each aerosol component assumed in the algorithm (Table 1) and the mass density for each aerosol component in Hess et al. [32]. The $\eta_{i, j}$ for AP, SS, and CGS depends on RH (see Section 2.2); thus, the $\eta_{i, j}$ was computed for various RH-values. Table 1 presents an example of the $\eta_{i, j}$, which was computed for $\mathrm{RH}=60 \%$.

\subsection{In-Situ Sampling Measurement (ACSA-12, MAAP, and Denuder-Filter Pack Method)}

A continuous dichotomous Aerosol Chemical Speciation Analyzer (ACSA-12 Monitor; Kimoto Electric Co., Ltd., Osaka, Japan) was used to measure sulfate $\left(\mathrm{SO}_{4}{ }^{-}\right)$, nitrate $\left(\mathrm{NO}_{3}{ }^{-}\right)$, water-soluble organic compounds (WSOC), and particulate matter $\left(\mathrm{PM}_{2.5}, \mathrm{PM}_{10}\right)$ with fine $\left(\mathrm{D}_{\mathrm{p}}<2.5 \mu \mathrm{m}\right)$ and coarse $\left(2.5 \mu \mathrm{m}<\mathrm{D}_{\mathrm{p}}<10 \mu \mathrm{m}\right)$ modes every hour [33]. The beta-ray absorption 
method was used to measure PM mass concentration [33]. Averaged $\mathrm{PM}_{2.5}$ for $24 \mathrm{~h}$ by ACSA is basically equivalent to the averaged $\mathrm{PM}_{2.5}$ measured by Federal Reference Method (FRM) of the US Environmental Protection Agency (EPA), which is the most reliable and standard method for $\mathrm{PM}_{2.5}$ measurement. Particulate matter is measured under a constant temperature $\left(21.5 \pm 1.5^{\circ} \mathrm{C}\right)$ and relative humidity $(35 \pm 5 \%)$ in ACSA. Sodium $\left(\mathrm{Na}^{+}\right)$and chloride $\left(\mathrm{Cl}^{-}\right)$were measured using Denuder-filter (D-F) pack measurements every 1 to 2 days in the regular observation period of August 2014 to October 2015. Coarse-mode particles were collected using a nuclepore membrane filter of $8.0 \mu \mathrm{m}$ pore size (111114; Nomura Micro Science Co., Ltd., Atsugi, Japan). Fine-mode particles were collected using a PTFE filter of $1 \mu \mathrm{m}$ pore size (J100A047A; ADVANTEC, Tokyo, Japan). The aerodynamic diameter of $50 \%$ collection efficiency of the nuclepore filter was $1.9 \mu \mathrm{m}$ with a flow rate of $16.7 \mathrm{~L} / \mathrm{min}$. This sum of fine and coarse mode $\mathrm{Na}^{+}$was converted to SS mass concentration based on the salinity and $\mathrm{Na}$ mass ratio of seawater [34]. The uncertainties of ACSA and D-F method for chemical compositions are less than $10 \% . \mathrm{PM}_{2.5}\left(\mathrm{PM}_{10}\right)$ measured using ACSA contains all aerosols smaller than $2.5 \mu \mathrm{m}$ $(10 \mu \mathrm{m})$. Therefore, in the comparison, lidar-derived $\mathrm{PM}_{2.5}$ (or $\mathrm{PM}_{10}$ ) was calculated as the sum of $\mathrm{BC}$, SS, AP, and MD under $2.5 \mu \mathrm{m}(10 \mu \mathrm{m})$. For in-situ measurement of BC, a multi-angle absorption photometer (MAAP; MAAP5012, Thermo Scientific, Waltham, MA, USA) was used with high temporal resolution. MAAP employs the filter-based light absorption technique. Kanaya et al. [35] reported that MAAP-derived BC values were systematically higher by a factor of 1.5 comparing to other techniques, therefore we conducted the data correction by multiplying a factor of $1 / 1.5$.

\section{Results}

Continuous aerosol measurements and simultaneous MMRL measurements were conducted from September 2014 to October 2015 at the Chikushi Campus of Kyushu University in Fukuoka. We first clarify the seasonal characteristics of optical properties and in-situ aerosol measurements. We then discuss direct aerosol comparisons between MMRL aerosol components and in-situ measurements, and the potential and limitations of the lidar algorithm to retrieve aerosol components.

\subsection{Seasonal Variation of Optical Properties and In-Situ Aerosol Measurements}

The aerosol field in the East Asian region is affected by meteorological variation (e.g., wind field, temperature, and RH) driven by the monsoon. To clarify seasonal variation of aerosols at Fukuoka, we summarized the seasonal mean value for optical properties and in-situ aerosol measurements during winter (December to February), spring (March to May), summer (June to August), and autumn (September to November) using the data from September 2014 to October 2015 (Table 2). Here, PM $\mathrm{C}_{\mathrm{c}} \mathrm{was}$ defined as $\left(\mathrm{PM}_{10}-\mathrm{PM}_{2.5}\right)$. Lidar-derived estimates were averaged vertically from 350 to $500 \mathrm{~m}$ for comparison with surface aerosol measurements.

Lidar-derived $\alpha_{355}$ and $\alpha_{532}$ were maximal in summer; however, $\mathrm{PM}_{2.5}$ observed using in-situ measurement was the lowest in summer. The fraction of fine-mode sulfate derived from in-situ measurements is highest in summer (35\%). These observations indicate that water uptake of sulfate particles increases aerosol extinction coefficients because $\mathrm{RH}$ is higher in summer in Japan. The mean $\mathrm{S}_{355}$ and $\mathrm{S}_{532}$ increase from winter to spring/summer ranging from 50 to $56 \mathrm{sr}$, although the variation is small. The behavior of seasonal variation of the CRs seems to differ in the wavelengths. $\mathrm{CR}_{532 / 1064}$ is lower in winter, spring and autumn than in summer, whereas $\mathrm{CR}_{355 / 532}$ is lower in summer. In general, $C R$ values decrease when there are more large particles, and vice versa. Thus, the seasonal behavior of $\mathrm{CR}_{532 / 1064}$ seems to be reasonable because typical large particles of DS increase in spring, due to long-range DS transportation from the Asian continent. Lidar-derived $\delta$ is relatively higher in spring, supporting that there is more DS in spring. Thus, the relatively lower $C_{355 / 532}$ in spring is affected by DS. However, the low $\mathrm{CR}_{355 / 532}$ in summer cannot be explained by DS transport. In addition, this low $\mathrm{CR}_{355 / 532}$ in summer cannot be explained by increase of SS particles in summer because SS mass concentration decreases in summer (Table 2). Thus, this feature of $\mathrm{CR}_{355 / 532}$ in summer may reflect increase of particle size of fine-mode particles (e.g., AP particles including water-soluble 
substances such as sulfate) by water uptake, because $C_{355 / 532}$ is more sensitive to smaller particles than $\mathrm{CR}_{532 / 1064}$, and vice versa.

Table 2. Seasonal mean optical properties in PBL and in-situ aerosol components and surface meteorological parameters observed at Fukuoka.

\begin{tabular}{|c|c|c|c|c|}
\hline & Winter (DJF) & Spring (MAM) & Summer (JJA) & Autumn (SON) \\
\hline$\alpha_{355}[/ \mathrm{km}]$ & $0.27 \pm 0.17^{2}$ & $0.26 \pm 0.14$ & $0.31 \pm 0.20$ & $0.22 \pm 0.12$ \\
\hline$\alpha_{532}[/ \mathrm{km}]$ & $0.17 \pm 0.12$ & $0.16 \pm 0.10$ & $0.22 \pm 0.20$ & $0.14 \pm 0.12$ \\
\hline $\mathrm{S}_{355}[\mathrm{sr}]$ & $53 \pm 20$ & $56 \pm 21$ & $56 \pm 18$ & $52 \pm 19$ \\
\hline $\mathrm{S}_{532}[\mathrm{sr}]$ & $50 \pm 18$ & $54 \pm 18$ & $53 \pm 19$ & $52 \pm 17$ \\
\hline$\delta_{355}[\%]$ & $7 \pm 4$ & $7 \pm 4$ & $4 \pm 2$ & $6 \pm 2$ \\
\hline$\delta_{532}[\%]$ & $10 \pm 7$ & $7 \pm 4$ & $2 \pm 1$ & $9 \pm 5$ \\
\hline $\mathrm{CR}_{355 / 532}$ & $1.7 \pm 0.72$ & $1.5 \pm 0.7$ & $1.5 \pm 0.48$ & $1.7 \pm 0.6$ \\
\hline $\mathrm{CR}_{532 / 1064}$ & $1.5 \pm 0.8$ & $1.6 \pm 1.0$ & $1.8 \pm 1.1$ & $1.5 \pm 0.8$ \\
\hline Num. of prof. 355 & 813 & 630 & 580 & 744 \\
\hline Num. of prof.532 & 719 & 584 & 583 & 728 \\
\hline $\mathrm{PM}_{2.5}\left[\mu \mathrm{g} / \mathrm{m}^{3}\right]$ & $21.0 \pm 13.7$ & $20.4 \pm 11.9$ & $15.0 \pm 10.5$ & $18.5 \pm 9.8$ \\
\hline $\mathrm{PM}_{\mathrm{c}}^{3}\left[\mu \mathrm{g} / \mathrm{m}^{3}\right]$ & $13.7 \pm 13.3$ & $15.4 \pm 13.7$ & $7.4 \pm 6.1$ & $9.2 \pm 4.9$ \\
\hline${ }_{\mathrm{f}} \mathrm{SO}_{4}{ }^{2-4}\left[\mu \mathrm{g} / \mathrm{m}^{3}\right]$ & $4.6 \pm 3.5\left(22 \%{ }^{5}\right)$ & $5.9 \pm 3.4(29 \%)$ & $5.3 \pm 3.9(35 \%)$ & $4.6 \pm 2.9(25 \%)$ \\
\hline${ }_{\mathrm{f}} \mathrm{NO}_{3}{ }^{-}\left[\mu \mathrm{g} / \mathrm{m}^{3}\right]$ & $2.6 \pm 2.2\left(12 \%^{5}\right)$ & $1.7 \pm 1.8(8 \%)$ & $0.7 \pm 0.5(4 \%)$ & $1.2 \pm 0.8(7 \%)$ \\
\hline${ }_{\mathrm{f}} \mathrm{WSOC}\left[\mu \mathrm{g} / \mathrm{m}^{3}\right]$ & $1.5 \pm 1.3\left(7 \%{ }^{5}\right)$ & $1.2 \pm 0.9(6 \%)$ & $0.6 \pm 0.8(4 \%)$ & $0.8 \pm 0.9(4 \%)$ \\
\hline $\mathrm{BC}\left[\mu \mathrm{g} / \mathrm{m}^{3}\right]$ & $1.1 \pm 0.7\left(5 \%^{5}\right)$ & $1.0 \pm 0.6(5 \%)$ & $0.9 \pm 0.5(6 \%)$ & $1.3 \pm 0.9(7 \%)$ \\
\hline${ }_{c} \mathrm{SO}_{4}{ }^{2-}\left[\mu \mathrm{g} / \mathrm{m}^{3}\right]$ & $0.8 \pm 0.5\left(6 \%^{6}\right)$ & $1.1 \pm 0.5(1 \%)$ & $1.2 \pm 1.0(16 \%)$ & $0.6 \pm 0.5(7 \%)$ \\
\hline${ }_{c} \mathrm{NO}_{3}-\left[\mu \mathrm{g} / \mathrm{m}^{3}\right]$ & $1.3 \pm 0.2\left(9 \%{ }^{6}\right)$ & $1.2 \pm 0.2(8 \%)$ & $0.7 \pm 0.1(9 \%)$ & $1.0 \pm 0.1(10 \%)$ \\
\hline${ }_{c} S S\left[\mu \mathrm{g} / \mathrm{m}^{3}\right]$ & $4.3 \pm 2.0\left(31 \%{ }^{6}\right)$ & $3.1 \pm 2.2(20 \%)$ & $1.7 \pm 1.1(22 \%)$ & $3.6 \pm 3.5(39 \%)$ \\
\hline RH [\%] & 58.5 & 56.3 & 67.8 & 56.3 \\
\hline Temp. $\left[{ }^{\circ} \mathrm{C}\right]$ & 7.7 & 17.1 & 26.6 & 19.6 \\
\hline
\end{tabular}

${ }^{1}$ Number of profiles; ${ }^{2}$ Values after \pm stand for standard deviations of the mean value; ${ }^{3}$ Subscript ' $c$ ' means coarse-mode $(2.5 \mu \mathrm{m}<$ diameter $<10 \mu \mathrm{m}) ;{ }^{4}$ Subscript ' $\mathrm{f}$ ' means fine-mode $(<2.5 \mu \mathrm{m}) ;{ }^{5}$ Fraction to $\mathrm{PM}_{2.5}$; ${ }^{6}$ Fraction to $\mathrm{PM}_{\mathrm{c}}$.

Seasonal variations of aerosol components obtained using in-situ measurements are as follows. Sulfate is higher in spring/summer compared to autumn/winter; nitrate and WSOC are higher in cold seasons (winter to spring); BC is lower somewhat in summer compared to autumn/winter; SS is lower in summer and is higher from autumn to winter; and $\mathrm{PM}_{2.5}$ and $\mathrm{PM}_{\mathrm{c}}$ are higher in winter and spring. Lidar-derived optical properties and in-situ aerosol measurements suggest that the mixing state of aerosols was complicated at Fukuoka, and water uptake of water-soluble small-size particles strongly affected the optical properties of aerosols in summer.

\subsection{Vertical Distribution of Four Aerosol Components}

We analyzed the vertical distributions of the lidar-derived aerosol components. Figure 2 presents a time-height cross section of lidar-derived aerosol mass concentration for (a) BC, (b) SS, (c) AP, (d) DS, (e) $\mathrm{PM}_{2.5}$, and (f) $\mathrm{PM}_{\mathrm{c}}$ from September 2014 to June 2017. Note that BC mass concentration was estimated based on the CGS model. Figure 3 presents the seasonal median vertical distribution of mass concentration for (a) BC, (b) SS, (c) AP, (d) DS, (e) $\mathrm{PM}_{2.5}$, and (f) $\mathrm{PM}_{\mathrm{c}}$. The vertical profiles are shown above ground. Column load, aerosol scale height $\mathrm{H}_{\mathrm{m}}$ (definition of $\mathrm{H}_{\mathrm{m}}$ is given in Appendix A and median mass concentration within PBL ( $350 \mathrm{~m}$ to $500 \mathrm{~m}$ ) for each component are summarized in Table 3. The aerosol scale height is an index of the vertical aerosol extent.

Seasonal variation of BC was not clear in Figure 2a. However, lidar-derived median vertical profile of mass concentration for BC shown in Figure 3 was maximal in summer around $700 \mathrm{~m}$. This summer peak may be caused by the overestimation of CGS as discussed in Section 3.3.1. The mass concentration by lidar was derived assuming dry state, however, the bias of relative humidity to the actual atmosphere might cause overestimation of $\mathrm{BC}$ in lidar analysis. Median vertical profile for AP also was maximal around $700 \mathrm{~m}$ in summer as shown in Figure 3c, this may be also affected by the 
bias of relative humidity during the season. SS mass concentration was higher in autumn and winter as seen in Figure 2b, indicating that this seasonal variation on the vertical distribution of SS matches with the seasonal variation of SS measured by D-F method at the ground surface (see Tables 2 and 3). The aerosol scale height for SS was lower than other aerosol components ranged from $1.14 \mathrm{~km}$ to $1.38 \mathrm{~km}$. Mass concentration for DS was higher from autumn to spring as seen in the previous section, and year-to-year variation was large (for example, there were hardly any strong dust storms in 2017, as shown in Figure 2). $\mathrm{PM}_{2.5}$ was clearly higher in winter and spring in Fukuoka, and the scale height ranged from $1.38 \mathrm{~km}$ to $1.62 \mathrm{~km}$. The seasonal variations of median mass concentration within PBL for each aerosol component estimated using lidar mostly match with in-situ ground-based aerosol measurements except for BC and AP in summer.

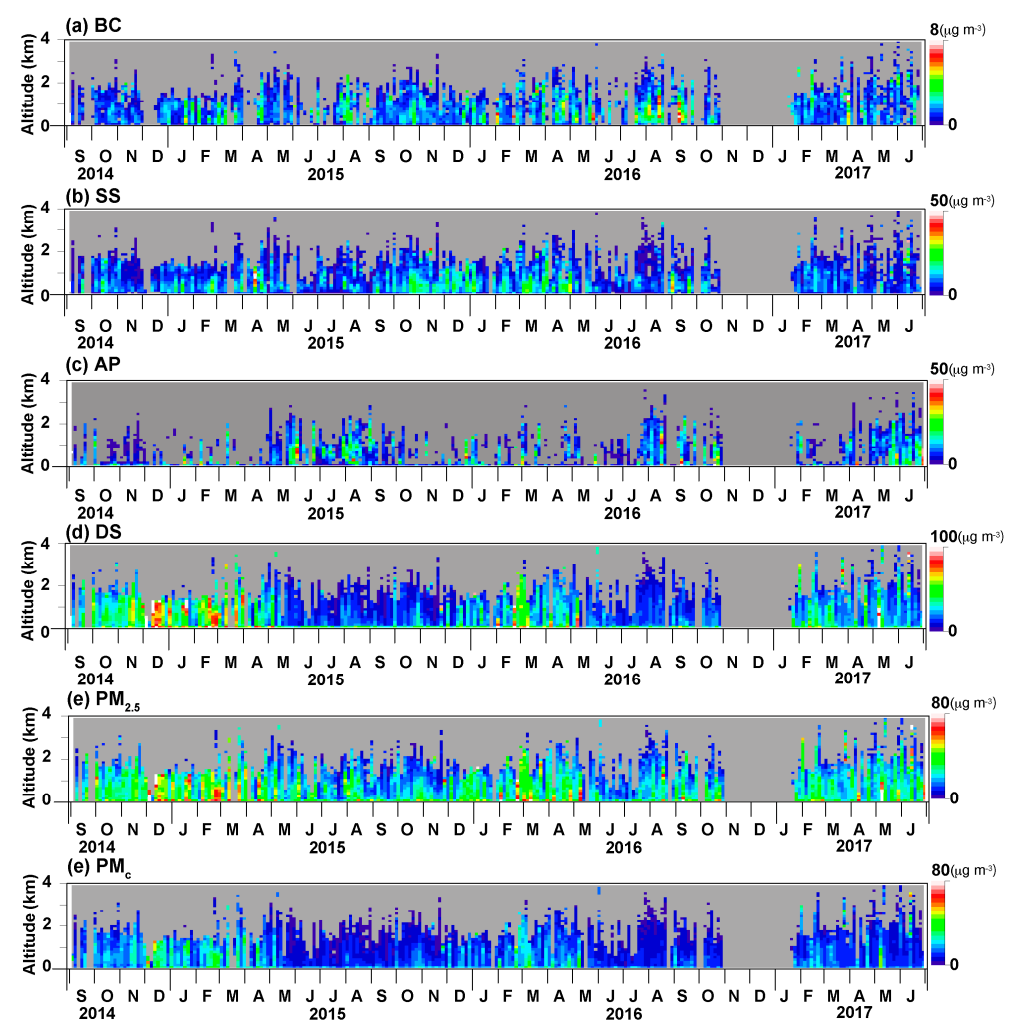

Figure 2. Time-height cross section of lidar-derived aerosol mass concentration for (a) BC, (b) SS, (c) AP, (d) DS, (e) $\mathrm{PM}_{2.5}$, and (f) $\mathrm{PM}_{\mathrm{c}}$.

Table 3. Seasonal means of aerosol column load (col), aerosol scale height $\left(\mathrm{H}_{\mathrm{m}}\right)$ and median mass concentration at PBL for each component ${ }^{1}$.

\begin{tabular}{ccccc}
\hline & Winter (DJF) & Spring (MAM) & Summer (JJA) & Autumn (SON) \\
\hline $\operatorname{colPM}_{2.5}\left(\mathrm{H}_{\mathrm{m}}\right)$ & $45.8(1.5)$ & $46.9(1.62)$ & $34.1(1.5)$ & $36.6(1.38)$ \\
$\operatorname{colPM}_{\mathrm{c}}\left(\mathrm{H}_{\mathrm{m}}\right)$ & $24.4(1.5)$ & $23.1(1.62)$ & $14.6(1.5)$ & $19.0(1.38)$ \\
$\mathrm{col}_{\mathrm{AP}}\left(\mathrm{H}_{\mathrm{m}}\right)$ & $5.5(1.26)$ & $9.2(1.38)$ & $9.9(1.5)$ & $5.4(1.38)$ \\
$\mathrm{col}_{\mathrm{BC}}\left(\mathrm{H}_{\mathrm{m}}\right)$ & $2.1(1.38)$ & $2.4(1.38)$ & $2.7(1.38)$ & $2.0(1.26)$ \\
$\mathrm{col}_{\mathrm{sS}}\left(\mathrm{H}_{\mathrm{m}}\right)$ & $11.8(1.26)$ & $11.7(1.38)$ & $8.4(1.38)$ & $11.1(1.14)$ \\
$\mathrm{col}_{\mathrm{DS}}\left(\mathrm{H}_{\mathrm{m}}\right)$ & $50.8(1.74)$ & $46.9(1.62)$ & $26.2(1.5)$ & $35.37(1.38)$ \\
$\mathrm{PM}_{2.5}$ & 23.9 & 22.9 & 16.4 & 21.3 \\
$\mathrm{PM}_{\mathrm{c}}$ & 13.1 & 11.1 & 7.8 & 11 \\
$\mathrm{AP}$ & 3.6 & 4.6 & 3.4 & 3.5 \\
$\mathrm{BC}$ & 1.2 & 1.5 & 1.6 & 1.2 \\
$\mathrm{SS}$ & 8.7 & 7.5 & 5 & 8.9 \\
$\mathrm{DS}$ & 24.3 & 21 & 13.3 & 19.4 \\
\hline
\end{tabular}

${ }^{1}$ The units of column load, $\mathrm{H}_{\mathrm{m}}$ and mass concentration are $\mathrm{mg} / \mathrm{m}^{2}, \mathrm{~km}$ and $\mu \mathrm{g} / \mathrm{m}^{3}$. 

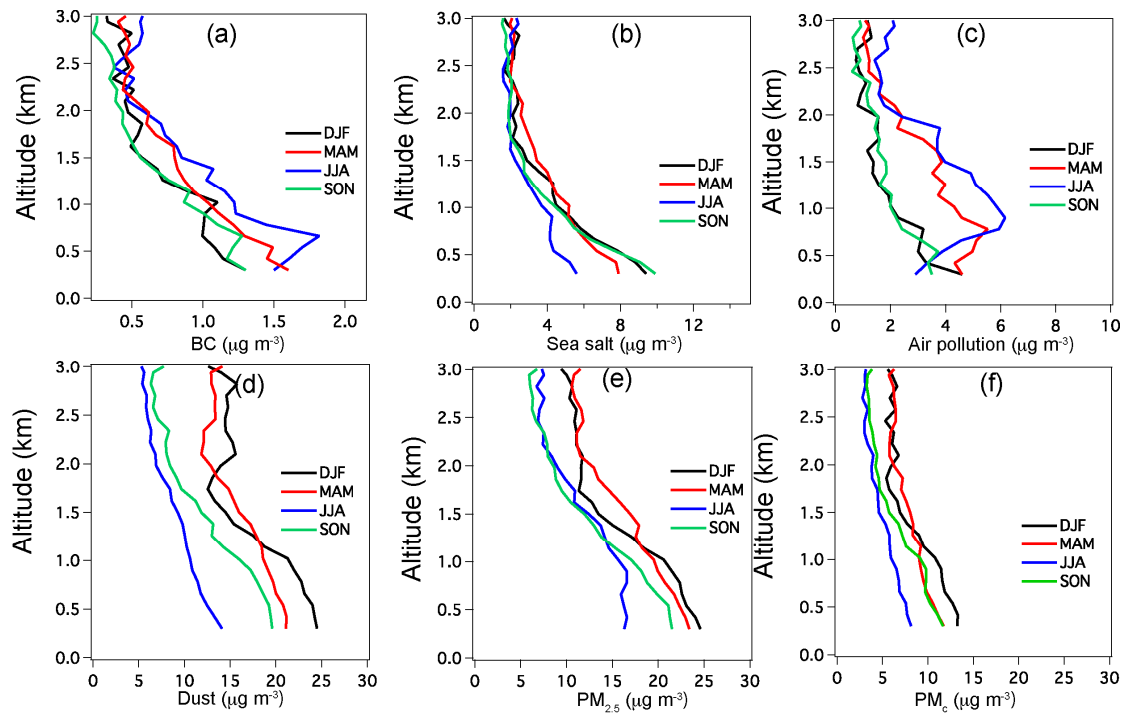

Figure 3. Seasonal median vertical distribution for (a) BC, (b) SS, (c) AP, (d) DS, (e) $\mathrm{PM}_{2.5}$, and (f) $\mathrm{PM}_{\mathrm{c}}$.

\subsection{Comparison of Aerosol Mass Concentration}

Figure 4 presents the daily comparison of lidar-derived mass concentrations with in-situ aerosol measurements of (a) BC, (b) SS, (c) $\mathrm{PM}_{2.5}$, (d) $\mathrm{PM}_{10}$, and (e) $\mathrm{PM}_{\mathrm{c}}$ at Fukuoka from September 2014 to October 2015. The lidar-derived estimates were averaged vertically from 350 to $500 \mathrm{~m}$, considering the overlap correction of MMRL. Except for D-F pack measurement, the lidar and in-situ measurement data were averaged in the nighttime. Time variations of aerosol components are strongly affected by meteorological conditions. Strong meteorological events such as typhoon (T) and dust storm (D) are denoted in Figure 4. The linear Pearson correlation coefficient $(R)$ and results of linear regression are shown within the Figure 4. The linear regressions were calculated using the results of the DS model with mode-radius of $1 \mu \mathrm{m}$. Tables 4 and 5 summarize optical properties and mass concentrations derived from lidar and significant meteorological parameters such as RH and in-situ aerosol mass concentration obtained from surface measurements (ACSA, MAAP, and D-F method) in several characteristic periods discussed below.

\subsubsection{Black Carbon}

The BC mass concentration derived using the pure BC model ranged from 1.1 to $30 \mu \mathrm{g} / \mathrm{m}^{3}$. The pure $B C$ model remarkably overestimated with respect to in-situ observation levels $(0.1$ to $3.2 \mu \mathrm{g} / \mathrm{m}^{3}$ ) with an Normalized Mean Bias (NMB) of $610 \%$ (formulation of NMB is given in Appendix B). In contrast, the CGS model drastically reduced the overestimation of $B C(N M B=26 \%)$. Aircraft observation conducted around Japan in 2004 indicated BC particles thickly coated with other aerosol components during transport [36]. These results suggested that the BC concentration level in Fukuoka could not be represented using the pure BC model, suggesting that aging of BC is an important process for trans-boundary BC. However, even though we applied the CGS model, we sometimes found remarkable overestimation of lidar-derived BC. Lidar-derived BC in periods B1 and B2 were 6 to 7 times higher than in-situ observation. During these periods, $S_{532}$ was relatively high and $\delta_{532}$ was considerably low (Table 4), implying that there were relatively many CGS particles and/or AP particles grown by water-uptake because the lidar ratios of CGS particles (Table 1) and grown AP particles (e.g., [37]) are generally high; and those particles are generally spherical (i.e., low $\delta$ ). In-situ surface measurements indicated that the main aerosol component during the analysis periods was sulfate, implying that misclassification of AP particles as CGS particles in the lidar retrieval might cause overestimation of BC mass concentration. The misclassification between AP and CGS particles can occur due to bias between RH data used in the retrieval and RH in the actual atmosphere and/or 
mismatching of the optical and microphysical properties for AP and CGS used in the algorithm with the aerosol properties in the actual atmosphere. RH bias affects the retrieval of AP more remarkably than that of CGS because the optical properties of AP directly related to the retrieval (e.g., $\mathrm{S}$ and CR) are more sensitive to $\mathrm{RH}$ than the optical properties of CGS.

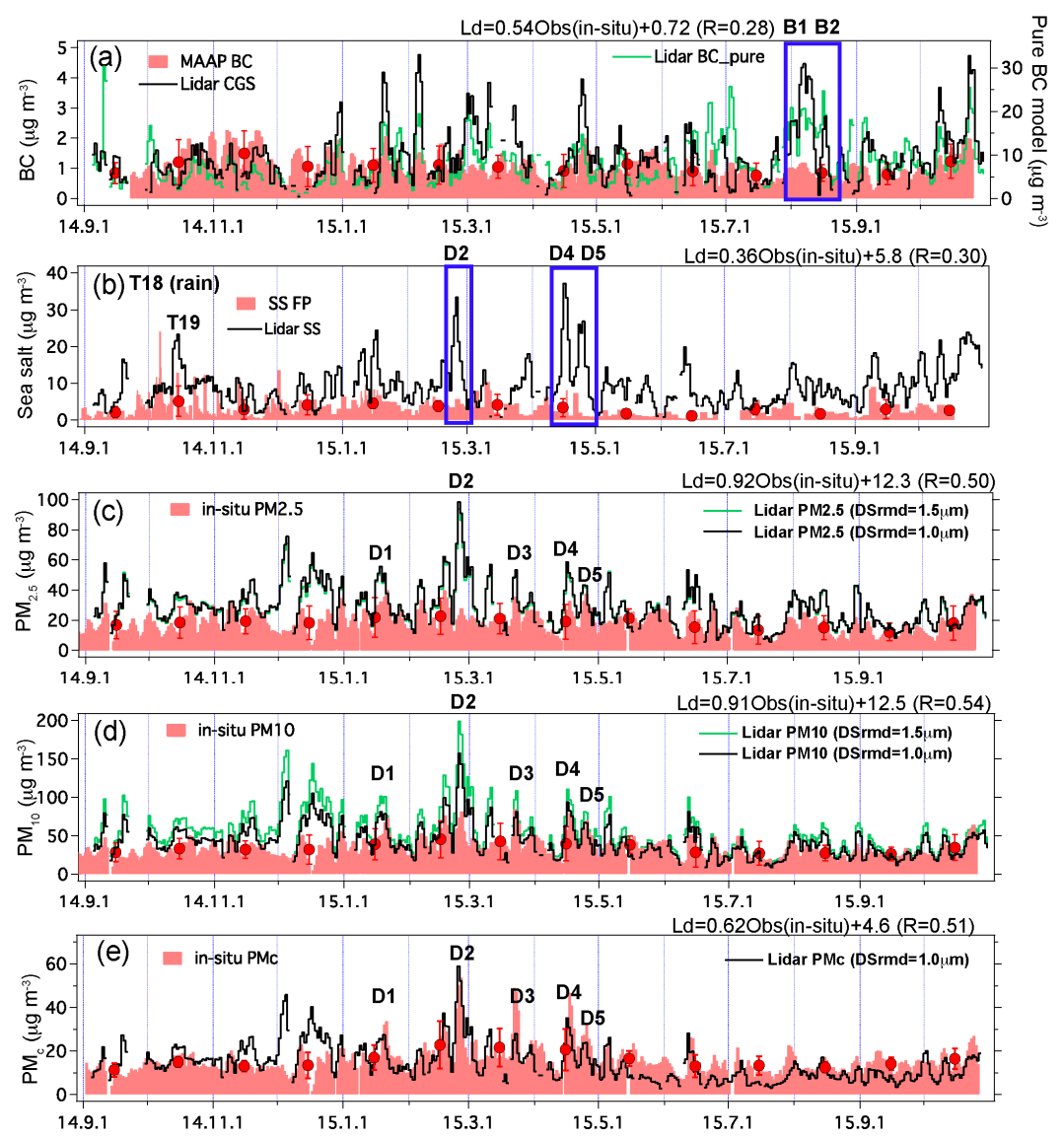

Figure 4. Daily comparison of lidar-derived mass concentrations with in-situ aerosol measurement of (a) BC, (b) SS, (c) $\mathrm{PM}_{2.5}$, (d) $\mathrm{PM}_{10}$, and (e) $\mathrm{PM}_{\mathrm{c}}$ at Fukuoka from September 2014 to October 2015. Red circle shows the monthly mean of in-situ aerosol mass concentration.

Table 4. Optical properties and aerosol mass concentrations derived from lidar observation.

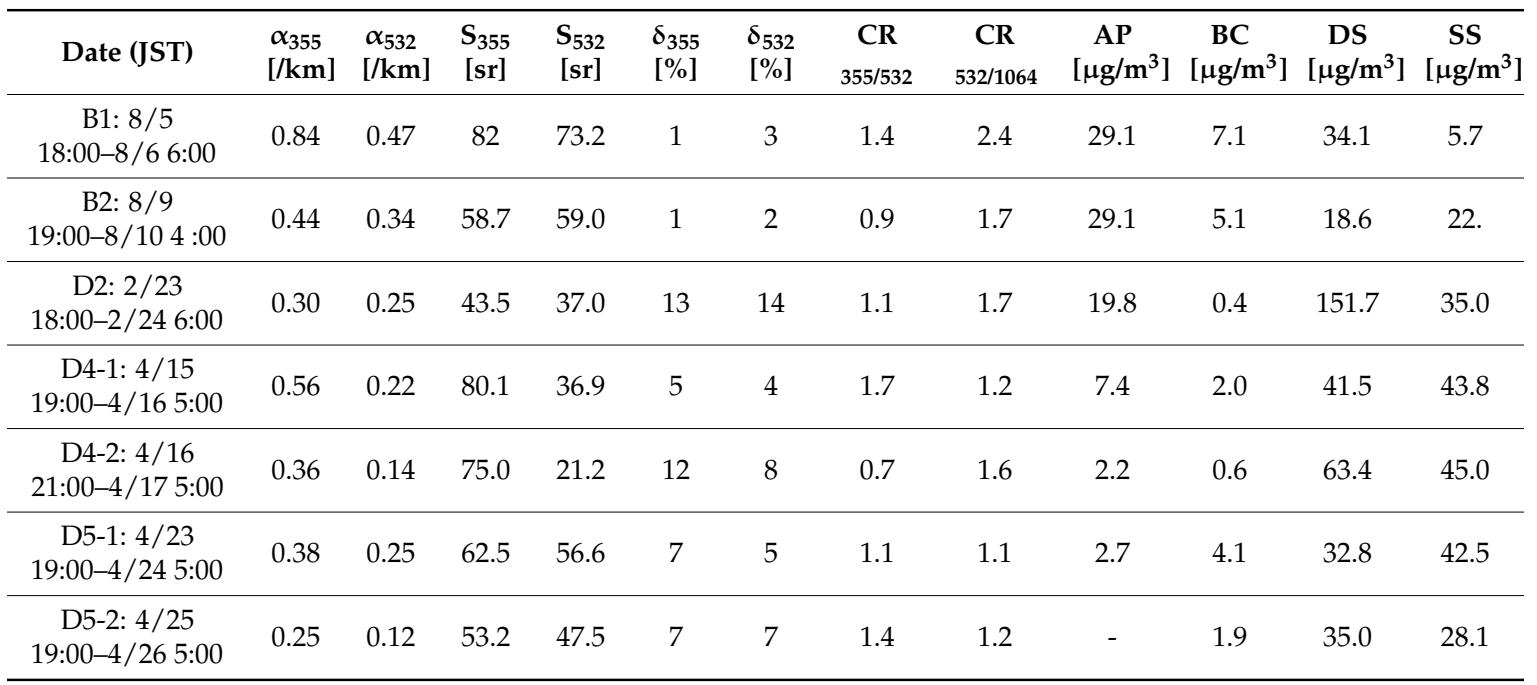


Table 5. Meteorological parameters and aerosol mass concentrations based on surface measurements.

\begin{tabular}{|c|c|c|c|c|c|c|c|c|c|c|c|}
\hline Date (JST) & $\begin{array}{l}\text { Temp } \\
{\left[{ }^{\circ} \mathrm{C}\right]}\end{array}$ & $\begin{array}{c}\mathrm{RH}^{1} \\
{[\%]}\end{array}$ & $\begin{array}{l}\text { RH_cor } \\
2[\%]\end{array}$ & $\begin{array}{c}\mathrm{PM}_{2.5} \\
{\left[\mu \mathrm{g} / \mathrm{m}^{3}\right]}\end{array}$ & $\begin{array}{c}\mathbf{P M}_{\mathbf{c}} \\
{\left[\mu \mathrm{g} / \mathrm{m}^{3}\right]}\end{array}$ & $\begin{array}{l}\mathrm{fSO}_{4}{ }^{2-4} \\
{\left[\mu \mathrm{g} / \mathrm{m}^{3}\right]}\end{array}$ & $\begin{array}{l}{ }_{\mathrm{f}} \mathrm{NO}_{3}^{-} \\
{\left[\mu \mathrm{g} / \mathrm{m}^{3}\right]}\end{array}$ & $\begin{array}{l}\mathrm{cSO}_{4}{ }^{2-5} \\
{\left[\mu \mathrm{g} / \mathrm{m}^{3}\right]}\end{array}$ & $\begin{array}{l}\mathrm{cNO}_{3}^{-} \\
{\left[\mu \mathrm{g} / \mathrm{m}^{3}\right]}\end{array}$ & $\begin{array}{c}\text { BC } \\
{\left[\mu \mathrm{g} / \mathrm{m}^{3}\right]}\end{array}$ & $\begin{array}{c}\mathrm{SS} \\
{\left[\mu \mathrm{g} / \mathrm{m}^{3}\right]}\end{array}$ \\
\hline $\begin{array}{c}\text { B1: 8/5 } \\
\text { 18:00-8/6 6:00 }\end{array}$ & $\begin{array}{l}28.9 \\
(30.1)\end{array}$ & $\begin{array}{l}73.0 \\
(77)^{\mathrm{c}}\end{array}$ & $\begin{array}{c}66.4 \\
(68)^{3}\end{array}$ & 32.3 & 15.3 & 14.8 & 0.43 & 2.2 & 0.5 & 1.1 & - \\
\hline $\begin{array}{c}\text { B2: } 8 / 9 \\
19: 00-8 / 104: 00\end{array}$ & $\begin{array}{l}28.1 \\
(29.6)\end{array}$ & $\begin{array}{l}76.1 \\
(81)\end{array}$ & $\begin{array}{l}64.1 \\
(73)\end{array}$ & 25.5 & 11.9 & 9.8 & 0.6 & 1.5 & 0.7 & 0.7 & 1.7 \\
\hline $\begin{array}{c}\text { D2: } 2 / 23 \\
18: 00-2 / 246: 00\end{array}$ & $\begin{array}{l}7.8 \\
(10.6)\end{array}$ & $\begin{array}{l}75.2 \\
(87)\end{array}$ & $\begin{array}{l}57.4 \\
(68)\end{array}$ & 33.1 & 87.9 & 4.8 & 3.3 & 1.8 & 4.1 & 2.3 & 5.8 \\
\hline $\begin{array}{c}\text { D4-1: 4/15 } \\
\text { 19:00-4/16 5:00 }\end{array}$ & $\begin{array}{l}15.2 \\
(16.4)\end{array}$ & $\begin{array}{l}56.8 \\
(72)\end{array}$ & $\begin{array}{l}54.6 \\
(55)\end{array}$ & 44.5 & 38.4 & 14.4 & 5.0 & 1.9 & 4.5 & 1.9 & 4.1 \\
\hline $\begin{array}{c}\text { D4-2: } 4 / 16 \\
\text { 21:00-4/17 5:00 }\end{array}$ & $\begin{array}{l}15.0 \\
(18.3)\end{array}$ & $\begin{array}{l}60.3 \\
(81)\end{array}$ & $\begin{array}{l}51.7 \\
(77)\end{array}$ & 29.3 & 53.3 & 7.5 & 2.2 & 1.9 & 3.5 & 0.9 & 8.1 \\
\hline $\begin{array}{c}\text { D5-1: 4/23 } \\
\text { 19:00-4/24 5:00 }\end{array}$ & $\begin{array}{l}14.3 \\
(16.7)\end{array}$ & $\begin{array}{l}79.7 \\
(89)\end{array}$ & $\begin{array}{l}33.7 \\
(39)\end{array}$ & 40.7 & 34.5 & 9.5 & 5.8 & 1.0 & 4.1 & 2.4 & 2.0 \\
\hline $\begin{array}{c}\text { D5-2: } 4 / 25 \\
\text { 19:00-4/26 5:00 }\end{array}$ & $\begin{array}{l}14.0 \\
(16.4)\end{array}$ & $\begin{array}{l}64.8 \\
(77)\end{array}$ & $\begin{array}{l}21.7 \\
(24)\end{array}$ & 37.0 & 30.8 & 12.0 & 3.2 & 1.4 & 3.0 & 2.0 & 1.1 \\
\hline
\end{tabular}

${ }^{1}$ Observed mean RH at the Fukuoka meteorological station of the Japan Meteorological Agency. ${ }^{2} \mathrm{RH}$ _cor means corrected RH based on modeled RH using the regression equation between the numerical model and observed surface RH. ${ }^{3}$ Maximum RH. ${ }^{4}$ Subscript ' $f$ ' means fine-mode $(<2.5 \mu \mathrm{m}) .{ }^{5}$ Subscript ' $c^{\prime}$ ' means coarse-mode $(2.5 \mu \mathrm{m}$ $<$ diameter $<10 \mu \mathrm{m}$ ).

We checked the RH data of GEOS-Chem $\left(\mathrm{RH}_{\text {model }}\right)$ using $\mathrm{RH}$ data observed at the surface $\left(\mathrm{RH}_{\mathrm{obs}}\right)$ throughout the analysis period and found positive bias of $\mathrm{RH}_{\text {model }}\left(\mathrm{RH}_{\text {model }}=0.66 \times \mathrm{RH}_{\mathrm{obs}}+23.4\right.$, $\mathrm{R}=0.63$ ). We then tried correcting the bias of the $\mathrm{RH}_{\text {model }}$ using the regression equation $\left(\mathrm{RH}_{\text {cor }}=\left(\mathrm{RH}_{\text {model }}-23.4\right) / 0.66\right)$ assuming that model biases are constant vertically, and re-estimated aerosol mass concentration using the $\mathrm{RH}_{\text {cor }}$ data. $\mathrm{BC}$ overestimation was reduced by $10 \%$; however, overestimation remained still because it is difficult to reduce the RH bias sufficiently, and the RH bias was still large (Table 5). Thus, it is essential to consider water-uptake of BC (and AP) appropriately and it would be effective to conduct simultaneous vertical measurement of RH with a water-vapor Raman lidar (e.g., [38]). It should be noted that the optical properties and mass concentration of aerosols presented in this paper were estimated using the $\mathrm{RH}_{\text {cor }}$ data from MMRL measurements. We also studied the sensitivity of the mode radius of CGS assumed in the algorithm to retrieve the uncertainty of $B C$ mass concentration. If we applied a smaller mode radius $(0.09 \mu \mathrm{m})$ in the CGS model, NMB increased $50 \%$ compared to the default mode radius $(0.11 \mu \mathrm{m})$. However, a larger mode radius $(0.14 \mu \mathrm{m})$ improved NMB by $25 \%$, although NMB for other components $\left(\mathrm{SS}, \mathrm{PM}_{2.5}\right.$ and $\left.\mathrm{PM}_{10}\right)$ became worse slightly by $5 \sim 7 \%$. These factors mentioned above induce uncertainty in the estimation of mass concentration.

\subsubsection{Sea Salt}

MMRL measurements generally captured the time variation of SS well except for typhoons, in which SS measured using the D-F method exhibited a sharp peak (T18 in Figure 4b). However, MMRL could not capture high and sharp SS concentrations due to strong signal attenuation by heavy rain. SS concentration derived by lidar tends to overestimate the in-situ measured concentration $(\mathrm{NMB}=153 \%)$ throughout the analysis period. We found notable overestimation of SS when DS particles were transported (Figure $4 \mathrm{~b}$ ). $\delta_{532}$ were smaller during these dust events $\left(4 \sim 14 \%\right.$ in D2, D4, and D5) than typical value for pure dust cases $\left(\delta_{532}>30 \%\right)$ (Table 4$)$. Backscatter CRs $\beta_{532} / \beta_{1064}$ were relatively small (1.1 to 1.7$)$, indicating relatively large particles. Coarse-mode nitrate mass concentration measured using ACSA was high (Table 5). These observations indicate the possibility of internal mixing of nitrate and DS particles. Internal mixture of DS and water-soluble substances tends to decrease $\delta_{532}$ (e.g., [39]). GEOS-Chem simulation including DS and SS acid uptake processes confirmed large-scale dust-nitrate outflows from the Asian continent to Fukuoka for all dust events in 2015 [25], supporting the possibility of internal mixing of DS with nitrate. Thus, the retrieval 
algorithm may partly misclassify internal mixing of DS as SS because the algorithm identifies large particles with a low particle linear depolarization ratio as SS. Considering the internal mixture of DS with water-soluble substances appropriately will lead to better classification and retrieval of SS particles (and DS), especially for aerosols in the East Asian region where dust-nitrate internal mixing frequently occurs [25,40].

\subsection{3. $\mathrm{PM}_{2.5}$ and $\mathrm{PM}_{10}$}

$\mathrm{PM}_{2.5}$ observed using ACSA was higher in winter and spring due to trans-boundary AP and DS from the Asian continent than in summer and autumn. The time variation of the lidar-derived $\mathrm{PM}_{2.5}$ is consistent with ACSA measurements, although the lidar-derived $\mathrm{PM}_{2.5}$ overestimates to some extent $\left(\mathrm{NMB}=56 \%\right.$ ). Overestimations of $\mathrm{PM}_{2.5}$ were large during dust events (especially in $\mathrm{D} 2$ ), implying that this $\mathrm{PM}_{2.5}$ overestimation may be mainly affected by overestimation of fine-mode DS particles. In addition, fine-mode SS particles may partly affect this overestimation of $\mathrm{PM}_{2.5}$ because the overestimation of SS turned out as mentioned before. The lidar derived $\mathrm{PM}_{10}$ overestimated by $25 \%$ in NMB but lidar-derived $\mathrm{PM}_{\mathrm{c}}$ agree well with ACSA-derived $\mathrm{PM}_{\mathrm{c}}$ when we used the DS model with mode-radius of $1 \mu \mathrm{m}$ (Figure 4e), implying that the overestimation of $\mathrm{PM}_{10}$ is caused by the overestimation of $\mathrm{PM}_{2.5}$. We investigated retrieval sensitivity of $\mathrm{PM}_{10}$ on the change of mode radius of the DS model. When we use the DS model with larger mode-radius, the overestimation of the $\mathrm{PM}_{10}$ becomes worse (e.g., $\mathrm{NMB}=55 \%$ for mode-radius of $1.5 \mu \mathrm{m}$ ) and the $\mathrm{PM}_{\mathrm{c}}$ is overestimated.

\section{Conclusions}

Intensive simultaneous aerosol observations using MMRL and in-situ surface aerosol measurements were conducted to clarify the mixing state of aerosol components and long-term variation at Fukuoka in western Japan from September 2014 to October 2015. Seasonal variation of optical properties and aerosol mass concentration was found based on MMRL and in-situ aerosol measurements. We evaluated an algorithm using $1 \alpha_{532}+2 \beta_{532,1064 a t t}+1 \delta_{532}$ data of the MMRL to retrieve extinction coefficients at $532 \mathrm{~nm}$ of four aerosol components (DS, BC, AP, and SS) assuming their microphysical and optical properties with in-situ aerosol measurements. For this purpose, aerosol mass concentration in the dry state was evaluated using the lidar-derived extinction coefficients for the aerosol components, using the similar assumptions as used in the aerosol component retrieval algorithm. The major findings are as follows.

(1) We summarized seasonal means of aerosol optical properties, in-situ aerosol mass concentrations, and meteorological parameters. The seasonal variation suggests that mixing of anthropogenic and natural aerosols (SS and DS), as well as hygroscopic growth of water-soluble aerosols may be key processes to produce aerosol seasonal variation in Fukuoka, in the downwind region of Japan.

(2) We found overestimation of lidar-derived BC mass concentration using the pure BC model; however, the use of the internal mixture model of $\mathrm{BC}$ with water-soluble substances (Core-Gray-Shell (CGS) model) drastically reduced BC overestimation. This suggests that using the CGS model is essential in estimating BC mass concentration from lidar measurements, at least in this Asian region.

(3) Systematic overestimation of BC mass concentration was found during summer, even though the CGS model was applied. The observations from in-situ and MMRL measurements implied misclassification of AP particles as CGS particles in the lidar retrieval. We found that this misclassification was at least partially caused by underestimation of model-reanalysis RH data used in the retrieval. Thus, use of more reliable vertical data of RH (e.g., sonde-derived or lidar-derived RH data) will lead to better estimation of BC (and AP). 
(4) The time variation of lidar-derived mass concentration of SS was generally consistent with in-situ aerosol measurements. However, we found some overestimation of SS mass concentration. In-situ and MMRL measurements suggested internal mixing between DS and nitrate during all dust events in 2015; this internal mixing may cause misclassification of DS as SS, and thus lead to overestimation of SS. The internal mixture of DS and water-soluble substances (e.g., nitrate and sulfate), as well as the mixture of BC and water-soluble substances will lead to better estimation of aerosol components.

(5) Time variations for lidar-derived $\mathrm{PM}_{2.5}, \mathrm{PM}_{10}$, and $\mathrm{PM}_{\mathrm{c}}$ were in good agreement with in-situ measurement. On the other hand, lidar sometimes overestimated $\mathrm{PM}_{2.5}$ and $\mathrm{PM}_{10}$ during a dust event, although the lidar-derived $\mathrm{PM}_{\mathrm{c}}$ agree well with in-situ measured $\mathrm{PM}_{\mathrm{c}}$. This implies that the overestimation of $\mathrm{PM}_{10}$ is caused by the overestimation of $\mathrm{PM}_{2.5}$, which is mainly affected by overestimation of fine-mode DS.

This study suggests that internal mixing of DS (or BC) and water-soluble substances and their hygroscopic growth should be considered in an aerosol retrieval algorithm using lidar data. The algorithm evaluated in this study uses only four channel data (i.e., $1 \alpha_{532}+2 \beta_{532}, 1064_{\text {att }}+1 \delta_{532}$ ).

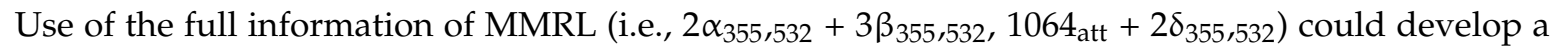
more advanced component retrieval algorithm that can more effectively consider internal mixture and water uptake of aerosols. Accurate estimates of aerosol components are essential in numerical data assimilation for aerosols and verification of space lidar measurements such as Earth Clouds, Aerosols and Radiation Explorer (EarthCARE) which is a joint Japanese (JAXA)-European (ESA) earth observation mission with high spectral resolution lidar (ATLID) [41].

Author Contributions: I.U. conceived and designed the synergetic aerosol observations at Chikushi Campus of Kyushu University, Japan; T.N. and N.S. performed the lidar setting and algorithm development; Y.H. analyzed the MMRL data; K.O. conducted chemical analysis of D-F pack samples; K.Y. performed the model simulation and provided RH data; R.K. and H.I. provided CGS model. Y.H. and T.N. prepared the paper with contributions from all coauthors.

Funding: This research was funded by the Japan Society for the Promotion of Science (JSPS), KAKENHI grant numbers JP25220101, JP15K16116, JP15H02808 and JP17H04477.

Acknowledgments: We thank Yusuke Kamiguchi at Nagoya University for the D-F pack sampling and chemical analysis and Shohei Kuwahara at Kyushu University for the D-F pack sampling.

Conflicts of Interest: The authors declare no conflict of interest.

\section{Appendix A}

The aerosol scale height $H_{m}$ [42] is defined as

$$
\int_{0}^{H_{m}} \alpha(z) d z=\tau_{a}\left(1-e^{-1}\right) \cong 0.6321 \tau_{a}
$$

where $\alpha(z)$ is the vertical profile of the aerosol extinction coefficient, and $\tau_{a}$ is the optical depth of aerosol.

\section{Appendix B}

Normalized Mean Bias (NMB) is defined as

$$
\mathrm{NMB}=\Sigma(\mathrm{M}-\mathrm{O}) / \Sigma(\mathrm{O}) \times 100
$$

where Lidar-derived mass concentration was substituted for $\mathrm{M}$, and in-situ mass concentration was substituted for $\mathrm{O}$. 


\section{References}

1. Zhang, X.Y.; Wang, Y.Q.; Niu, T.; Zhang, X.C.; Gong, S.L.; Zhang, Y.M.; Sun, J.Y. Atmospheric aerosol compositions in China: Spatial/temporal variability, chemical signature, regional haze distribution and comparisons with global aerosols. Atmos. Chem. Phys. 2012, 12, 779-799. [CrossRef]

2. Huang, X.; Liu, Z.; Liu, J.; Hu, B.; Wen, T.; Tang, G.; Zhang, J.; Wu, F.; Ji, D.; Wang, L.; et al. Chemical characterization and source identification of $\mathrm{PM}_{2.5}$ at multiple sites in the Beijing-Tianjin-Hebei region, China. Atmos. Chem. Phys. 2017, 17, 12941-12962. [CrossRef]

3. Zhao, B.; Liou, K.N.; Gu, Y.; Li, Q.; Jiang, J.H.; Su, H.; He, C.; Tseng, H.L.R.; Wang, S.; Liu, R.; et al. Enhanced PM2.5 Pollution in China due to aerosol-cloud interactions. Sci. Rep. 2017, 7, 4453. [CrossRef] [PubMed]

4. IPCC. The Fifth Assessment Report of the Intergovernmental Panel on Climate Change; IPCC: Geneva, Switzerland, 2013.

5. Omar, A.H.; Winker, D.M.; Kittaka, C.; Vaugham, M.A.; Liu, Z.; Hu, Y.; Trepte, C.R.; Rogers, R.R.; Ferrare, R.A.; Lee, K.P.; et al. The CALIPSO automated aerosol classification and lidar ratio selection algorithm. J. Atmos. Ocean Technol. 2009, 26, 1994-2014. [CrossRef]

6. Burton, S.P.; Ferrare, R.A.; Vaugham, M.A.; Omar, A.H.; Rogers, R.R.; Hostetler, C.A.; Hair, J.W. Aerosol classification from airbore HSRL and comparisons with the CALIPSO vertical feature mask. J. Atmos. Meas. Technol. 2013, 6, 1397-1412. [CrossRef]

7. Ansmann, A.; Riebesell, M.; Wandinger, U.; Weitkamp, C.; Michaelis, W. Combined Raman elastic-backscatter LIDAR for vertical profiles of moisture, particle extinction, backscatter and LIDAR ratio. Appl. Phys. 1992, 55, 18-28. [CrossRef]

8. Müller, D.; Ansmann, A.; Mattis, I.; Tesche, M.; Wandinger, U.; Althausen, D.; Pisani, G. Aerosol-typedependent lidar ratios observed with Raman lidar. J. Geophys. Res. 2007, 112, D16202. [CrossRef]

9. Burton, S.P.; Ferrare, R.A.; Hostetler, C.A.; Hair, J.W.; Rogers, R.R.; Obland, M.D.; Butler, C.F.; Cook, A.L.; Harper, D.B.; Froyd, K.D. Aerosol classification using airborne High Spectral Resolution Lidar measurements-methodology and examples. Atmos. Meas. Technol. 2012, 5, 73-98. [CrossRef]

10. Sugimoto, N.; Uno, I.; Nishikawa, M.; Shimizu, A.; Matsui, I.; Dong, X.; Chen, Y.; Quan, H. Record heavy Asian dust in Beijing in 2002: Observations and model analysis of recent events. Geophys. Res. Lett. 2003, 30, 1640. [CrossRef]

11. Kanatani, K.T.; Ito, I.; Al-Delaimy, W.K.; Adachi, Y.; Mathews, W.C.; Ramsdell, J.W. Desert dust exposure is associated with increased risk of asthma hospi-talization in children. Am. J. Respir. Crit. Care Med. 2010, 182, 1475-1481. [CrossRef] [PubMed]

12. Onishi, K.; Kurosaki, Y.; Otani, S.; Yoshida, A.; Sugimoto, N. Atmospheric transport route determines components of Asian dust and health effect in Japan. Atmos. Environ. 2012, 49, 94-102. [CrossRef]

13. Shimizu, A.; Sugimoto, N.; Matsui, I.; Mori, I.; Nishikawa, M.; Kido, M. Relationship between Lidar-derived Dust Extinction Coeffcients and Mass Concentrations in Japan. Sola 2011, 7A, 1-4. [CrossRef]

14. Kaneyasu, N.; Sugimoto, N.; Shimizu, A.; Yamamoto, S.; Kawamoto, K. Comparison of Lidar-derived dust extinction coefficients and the mass concentrations of surface aerosol. J. Jpn. Soc. Atmos. Environ. 2012, 47, 285-291. [CrossRef] (In Japanese with English Abstract)

15. Tesche, M.; Ansmann, A.; Müller, D.; Althausen, D.; Engelmann, R.; Freudenthaler, V.; Gro $\beta$, S. Vertically resolved separation of dust and smoke over Cape Verde using multiwavelength Raman and polarization lidars during Saharan Mineral Dust Experiment 2008. J. Geophys. Res. 2009, 114, D13202. [CrossRef]

16. Tesche, M.; Müller, D.; Gross, S.; Ansmann, A.; Althausen, D.; Freudenthaler, V.; Weinzierl, B.; Veira, A.; Petzold, A. Optical and microphysical properties of smoke over Cape Verde inferred from multiwavelength lidar measurements. Tellus B 2011, 63, 677-694. [CrossRef]

17. Nishizawa, T.; Sugimoto, N.; Matsui, I.; Shimizu, A.; Tatarov, B.; Okamoto, H. Algorithm to retrieve aerosol optical properties from high-spectral-resolution lidar and polarization Mie-scattering lidar measurements. IEEEE Trans. Geosci. Remote Sens. 2008, 46, 4094-4103. [CrossRef]

18. Nishizawa, T.; Sugimoto, N.; Matsui, I.; Shimizu, A.; Hara, Y.; Uno, I.; Yasunaga, K.; Kudo, R.; Kim, S.W. Ground-based network observation using Mie-Raman lidars and multi-wavelength Raman lidars and algorithm to retrieve distribution of aerosol components. J. Quant. Spectr. Radiat. Transf. 2017, 188, 79-93. [CrossRef] 
19. Hara, Y.; Nishizawa, T.; Sugimoto, N.; Matsui, I.; Pan, X.; Kobayashi, H.; Osada, K.; Uno, I. Optical properties of mixed aerosol layers over Japan derived with multi-wavelength Mie-Raman lidar system. J. Quant. Spectr. Radiat. Transf. 2017, 188, 20-27. [CrossRef]

20. Pan, X.L.; Uno, I.; Hara, Y.; Kuribayashi, M.; Kobayashi, H.; Sugimoto, N.; Yamamoto, S.; Shimohara, T.; Wang, Z. Observation of the simultaneous transport of Asian mineral dust aerosols with anthropogenic pollutants using a POPC during a long-lasting dust event in late spring 2014. Geophys. Res. Lett. 2015, 42, 1593-1598. [CrossRef]

21. Pan, X.L.; Uno, I.; Hara, Y.; Osada, K.; Yamamoto, S.; Wang, Z.; Sugimoto, N.; Kobayashi, H.; Wang, Z.F. Polarization properties of aerosol particles over western Japan: Classification, seasonal variation, and implications for air quality. Atmos. Chem. Phys. 2016, 16, 9863-9873. [CrossRef]

22. Itahashi, S.; Hayami, H.; Uno, I.; Pan, X.L.; Uematsu, M. Importance of coarse-mode nitrate produced via sea salt as atmospheric input to east Asian oceans. Geophys. Res. Lett. 2016, 43, 5483-5491. [CrossRef]

23. Itahashi, S.; Hayami, H.; Yumimoto, K.; Uno, I. Chinese province-scale source apportionments for sulfate aerosol in 2005 evaluated by the tagged tracer method. Environ. Pollut. 2017, 220, 1366-1375. [CrossRef] [PubMed]

24. Osada, K.; Kamikuchi, T.; Yamamoto, S.; Kuwahara, S.; Pan, X.; Hara, Y.; Uno, I. Comparison of ionic concentrations on size-segregated atmospheric aerosol particl based on a denuer-filter method and a Continuous Dichotomous Aerosol Chemical Speciation Analyzer (ACSA-12). Earozoru Kenkyu 2016, 31, 203-209. [CrossRef] (In Japanese with English Abstract)

25. Uno, I.; Osada, K.; Yumimoto, K.; Wang, Z.; Itahashi, S.; Pan, X.; Hara, Y.; Kanaya, Y.; Yamamoto, S.; Fairlie, T.D. Seasonal variation of fine- and coarse-mode nitrates and related aerosols over East Asia: Synergetic observations and chemical transport model analysis. Atmos. Chem. Phys. 2017, 17, 14181-14197. [CrossRef]

26. Dubovik, O.; Sinyuk, A.; Lapyonok, T.; Holben, B.N.; Mishchenko, M.; Yang, P.; Eck, T.F.; Volten, H.; Muñoz, O.; Veihelmann, B.; et al. Application of spheroid models to account for aerosol particle nonsphericity in remote sensing of desert dust. J. Geophys. Res. 2006, 111, D11208. [CrossRef]

27. D'Almeida, G.; Koepke, P.; Shettle, E.P. Atmospheric Aerosols: Global Climatology and Radiative Characteristics; A Deepak Pub.: Hampton, VA, USA, 1991; p. 561, ISBN-13 978-0937-194225.

28. Kahnert, M.; Nousiainen, T.; Lindqvist, H. Models for integrated and differential scattering optical properties of encapsulated light absorbing carbon aggregates. Opt. Express 2013, 21, 7974-7993. [CrossRef] [PubMed]

29. Fuller, K.A.; Malm, W.C.; Kreidenweis, S.M. Effects of mixing on extinction by carbonaceous particles. J. Geophys. Res. 1999, 104, 15941-15954. [CrossRef]

30. Garnett, J.C.M. Colours in meatal glasses and in metallic films. Philos. Trans. Soc. 1904, 203, 385-420. [CrossRef]

31. Matsui, H.; Koike, M.; Kondo, Y.; Moteki, N.; Fast, J.D.; Zaveri, R.A. Development and validation of a black carbon mixing state resolved three-dimensional model: Aging processes and radiative impac. J. Geophys. Res. 2013, 118, 2304-2326. [CrossRef]

32. Hess, M.; Koepke, P.; Schult, I. Optical properties of aerosols and clouds: The software package OPAC. Bull. Am. Meteorol. Soc. 1998, 79, 831-844. [CrossRef]

33. Kimoto, H.; Ueda, A.; Tsujimoto, K.; Mitani, Y.; Toyasaki, Y.; Kimoto, T. Development of continuous dichotomous aerosol chemical speciation analyzer. Clean Technol. 2013, 23, 49-52. (In Japanese)

34. Keene, W.C.; Pszenny, A.A.P.; Galloway, J.N.; Hawley, M.E.T. Sea-salt corrections and interpretation of constituent ratios in marine precipitation. J. Geophys. Res. 1986, 91, 6646-6658. [CrossRef]

35. Kanaya, Y.; Taketani, F.; Komazaki, Y.; Liu, X.; Kondo, Y.; Sahu, L.K.; Irie, H.; Takashima, H. Comparison of Black carbon mass concentrations observed by Multi-Angle Absorption Photometer (MAAP) and Continuous Soot0Monitoring System (COSMOS) on Fukue Island and in Tokyo, Japan. Atmos. Meas. Technol. 2012, 47, 1-10. [CrossRef]

36. Oshima, N.; Koike, M.; Zhang, Y.; Kondo, Y. Aging of black carbon in outflow from anthropogenic sources using a mixing state resolved model: 2 . Aerosol optical properties and cloud condensation nuclei activities. J. Geophys. Res. 2009, 114, D18202. [CrossRef]

37. Ackermann, J. The extinction-to-backscatter ratio of tropospheric aerosol: A numerical study. J. Atmos. Ocean. Technol. 1998, 15, 1043-1050. [CrossRef] 
38. Bellenger, H.; Yoneyama, K.; Katsumata, K.; Nishizawa, T.; Yasunaga, K.; Shirooka, R. Observation of moisture tendencies related to shallow convection. J. Atmos. Sci. 2015, 72, 641-659. [CrossRef]

39. Sugimoto, N.; Nishizawa, T.; Shimizu, A.; Matsui, I.; Kobayashi, H. Detection of internally mixed Asian dust wit air pollution aerosols using a polarization optical particle counter and a polarization-sensitive two-wavelength lidar. J. Quant. Spectr. Radiat. Transf. 2014, 150, 107-113. [CrossRef]

40. Pan, X.; Uno, I.; Wang, Z.; Nishizawa, T.; Sugimoto, N.; Yamamoto, S.; Kobayashi, H.; Sun, Y.; Fu, P.; Tang, X.; et al. Real-time observational evidence of changing Asian dust morphology with the mixing of heavy anthropogenic pollution. Sci. Rep. 2016, 7, 335. [CrossRef] [PubMed]

41. Illingworth, A.J.; Berker, H.W.; Beljaars, A.; Ceccaldi, M.; Chepfer, H.; Clerbaux, N.; Cole, J.; Delanoë, J.; Domenech, C.; Donovan, D.P.; et al. The EarthCARE satellite: The next step forward in global measurements of clouds, aerosols, precipitation, and radiation. Bull. Am. Meteorol. Soc. 2015, 96, 1311-1332. [CrossRef]

42. Hayasaka, T.; Satake, S.; Shimizu, A.; Sugimoto, N.; Matsui, I.; Aoki, K.; Muraji, Y. Vertical distribution and optical properties of aerosols observed over Japan during the Atmospheric Brown Clouds-East Asia Regional Experiment 2005. J. Geophys. Res. 2007, 112, D22S35. [CrossRef]

(C) 2018 by the authors. Licensee MDPI, Basel, Switzerland. This article is an open access article distributed under the terms and conditions of the Creative Commons Attribution (CC BY) license (http://creativecommons.org/licenses/by/4.0/). 